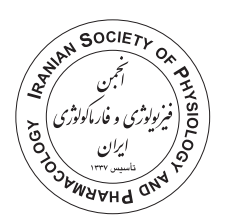

\title{
The protective effects of apigenin on OLN-93 cellular model of cerebral stroke
}

\author{
Samira Miraee ${ }^{1}$, Mona Farhadi ${ }^{*}$ (iD), Seyed Behnamedin Jameie ${ }^{2,3}$, Shabnam Najafi ${ }^{2}$
}

1. Department of Microbiology, Karaj Branch, Islamic Azad University, Karaj, Iran

2. Neuroscience Research Center, Iran University of Medical Sciences, Tehran, Iran

3. Department of Medical Basic Sciences, Faculty of Allied Medicine, Iran University of Medical Sciences, Tehran, Iran

\begin{abstract}
Introduction: Cerebral stroke is known to be the third most common cause of death in the world. To study pathophysiology and effects of the therapeutic agents on stroke, the cellular model of stroke recently was used more. ONL-93, oligodendrocyte like cell, is known as an appropriate model to study the role of glial cells in stroke. Apigenin is a flavonoid that has neuroprotective and neurogenic effects; therefore, the purpose of this study was to investigate the role of apigenin flavonoid on the OLN-93 cell line in terms of oxygen and glucose deprivation in the cellular stroke model.

Methods: The cells were divided into experimental, negative and positive control groups. Then, MTT, reactive oxygen species (ROS), annexin and propidium iodide as well as Western blotting assays were performed to evaluate the viability and apoptosis.

Results: The results showed that there was a significant increase in the number of live cells following administration of $1 \mu \mathrm{M}$ of apigenin in experimental groups and also, there was a significant difference in the number of live cells between two doses of $1 \mu \mathrm{M}$ and $0.75 \mu \mathrm{M}$ of the apigenin. The amount of ROS produced at a concentration of $1 \mu \mathrm{M}$ apigenin was a significant decrease compared to the positive control group and apoptotic cells also decreased significantly. The results for the expression of P53 protein showed a significant reduction in experimental groups.

Conclusion: Based on our results, apigenin could have beneficial effects through the reduction of $\mathrm{P} 53$ and ROS production.
\end{abstract}

\section{Introduction}

Oligodendrocytes are known for their abilities in myelination in the central nervous system. Different neurological diseases influence the viability and the function of oligodendrocytes that leads to mild to severe damage

\author{
Keywords: \\ Oxygen and glucose deprivation \\ Apigenin \\ Apoptosis \\ OLN-93 cell line
}

* Corresponding author: Mona Farhadi, mona.farhadi@kiau.ac.ir

Received 9 September 2020; Revised from 21 October 2020; Accepted 27 October 2020

Citation: Miraee S, Farhadi M, Jameie SB, Najafi S. The protective effects of apigenin on OLN-93 cellular model of cerebral stroke. Physiology and Pharmacology 2021; 25: 270-278. http://dx.doi.org/10.52547/ppj.25.3.270 
The formation and integration of myelin is not only an essential process in the formation of the nervous system, but also plays an important role in neuroprotection and repair. It is reported that 5.6 million people survive each year after CVA and stroke (Logan et al., 2018) but, most surviving people suffering from a disability, thus putting a heavy burden on themselves, the family and the community. So far, many efforts have been made to prevent and reduce the side effects of stroke. Due to the role of oligodendrocytes in physiology and pathology in the central nervous system, they have received more pay attention to neurological diseases such as stroke (Solanki et al., 2015). Because of the importance of them, the oligodendrocyte cell line OLN-93 has developed recently to study their response to injury and repair. The use and application of herbal materials such as flavonoids to improve the function of damaged neurons and neuroglia have been considered by many scholars. Flavonoids are an important family of polyphenolic compounds that are widely used in the territory of plants. Their healing and repair properties are well known since ancient Greece. They have numerous biological effects, such as inhibition of tumor growth and regulation of inflammatory responses (Solanki et al., 2016). Apigenin with the chemical name (4, 5, 7-trihydroxy flavones) is an effective flavonoid of chamomile and is of the methoxyflavone species. These compounds follow a general structure of phenylbenzopyran (C6-C3-C6) and are basically divided into flavones and isoflavones, flavonols, flavanones and flavanonols according to the degree of saturation and the type of opening of the central pyran ring (Haghiroalsadat et al., 2012; Miean and Mohamed, 2001). This flavonoid is present in apple, celery, grapefruit, and wheat sprout (Haghiroalsadat et al., 2012). Several in vivo and in vitro studies have shown that apigenin has potent anti-inflammatory, anti-cancerous and antioxidant effects. These antioxidant effects are exerted through suppression of oxidative stress and free radical and increased intracellular antioxidant defense regulation, such as increased glutathione levels (Balez et al., 2016; Nabavi et al., 2018). Pang et al. (2018) reported that apigenin improves stroke by altering the histone acetylation in mice. They also showed that apigenin inhibits cell death in endothelial cells under conditions of reduced oxygen and glucose, which is performed via the caveolin-1/VEGF route. Caltagirone et al. (2000) investigated the inhibitory effect of apigenin and quercetin on melanoma B16-
BL6 and its metastatic potential. They found that these polyphenolic compounds prevented the growth of melanoma cells in vitro. Su et al. (2020) reported that hyaluronidase activity prevents oligodendrocyte progenitor cells (OPCs) maturation and blocks myelination or remyelination, and that selective hyaluronidase inhibitors can be used to accelerate myelination or remyelination following CNS injuries. They used a modified flavonoid and found this novel inhibitor promotes OPC maturation in the presence of high molecular weight forms of the glycosaminoglycan hyaluronan in vitro. Their study has shown that the blocking hyaluronidase activity with this modified apigenin extract accelerates OPC maturation in a slice culture model of perinatal white matter injury. Taupin et al. (2009) evaluated the effects of apigenin and its compounds on adult neurogenesis in vivo and in vitro and they found that apigenin stimulates memory learning and function. In another research, the anti-cancerous effect of apigenin on A2780 mouse ovarian cancer cells was reported. According to that study, the apigenin ceases the cell division through beta-estrogen receptors ( $\mathrm{Li}$ et al., 2009). It is also shown that the apigenin has the ability to inhibit the inflammation caused by reactive oxygen species (ROS) production by lipopolysaccharide in endothelial cells and is also capable of inhibiting apoptosis through caspase3 pathway (Duarte et al., 2013). Souza et al. (2015) evaluated the effect of apigenin on multipotent and pluripotent stem cells. They showed that apigenin increases the expression of neuronal differentiation factors. Their findings showed that apigenin causes differentiation of stem cells into the neuron via estrogen receptor and RAR signaling, and improves their functional differentiation to the neuron.

Apigenin as an antioxidant is used to promote neurogenesis and it can prevent apoptotic damage. In order to study the protective effect of apigenin on cellular model of stroke- induced via oxygen and glucose deprivation (OGD) the present study was designed.

\section{Material and methods}

The OLN-93 cell line was purchased from the Iranian Biological Resource Center (IBRC). RPMI-1640 media was purchased from Sigma-Aldrich and fetal bovine serum (FBS) purchased from GIBCO. Penicillin-streptomycin, 3-[4,5-Dimethylthiazol-2-yl]-2,5-diphenyl- tetrazolium bromide (MTT), P53 primary and secondary antibodies, as well as Annexin \& PI kit were 
purchased from Sigma Chemical Co. (St. Louis, MO, USA).

\section{Cell culture}

Cells were cultured in RPMI medium containing 10\% FBS as well as penicillin and streptomycin. They were then incubated at $37^{\circ} \mathrm{C}$ with $5 \%$ carbon dioxide and $95 \%$ humidity. After three passages, cells were used for the study.

\section{Experimental groups}

The cells were divided into negative control (without treatment), positive control (oxygen and glucose deprivation, $\mathrm{Glu} / \mathrm{O} 2 \mathrm{D}$,) and experimental groups (Glu/O2D + $0.25,0.5,0.75$ and $1 \mu \mathrm{M}$ apigenin).

\section{Oxygen and glucose deprivation}

OGD is the method for the stroke model, in vitro (Tornabene et al., 2019). In this treatment first cells cultured in medium without glucose for half an hours then OGD experiments were performed in a hypoxia workbench in a chamber with two outlet valve, with an atmosphere of $1 \% \mathrm{O} 2,10 \% \mathrm{CO} 2$ and $89 \% \mathrm{~N} 2$ and a temperature of $37^{\circ} \mathrm{C}$ for $1 \mathrm{~h}$. After that, the medium was removed and a concentrated solution of glucose was added to the cell medium of the OGD-treated cells and the cells were transferred back to the normal incubator $(90 \%$ room air- $10 \% \mathrm{CO} 2,37^{\circ} \mathrm{C}$ ) for $24 \mathrm{~h}$. For experimental group, after culturing the cells, they were treated with apigenin for $3 \mathrm{~h}$ and then placed in glucose-free medium for half an hour and in the OGD chamber for 1h under oxygen deprivation conditions. After this period, the medium was emptied on the cells and placed again in the medium containing glucose and apigenin for $24 \mathrm{~h}$ in incubator.

\section{MTT assay}

In order to carry out this test, 5000 cells were cultured in each well of the 96-well plates. After one day, cells were exposed to deprivation of glucose and oxygen for one hour and then treated with $0.25,0.5,0.75$ and $1 \mu \mathrm{M}$ apigenin for $24 \mathrm{~h}$. Finally, MTT color was added and the OD level was evaluated by ELISA reader. The following formula was used to evaluate the cellular viability.

$$
\text { Viability }=\frac{O D \text { sample }}{O D \text { control }} \times 100
$$

\section{ROS assay}

Cells were cultured in a 12-well plate and treated. After $12 \mathrm{~h}$, each well was emptied and washed with $1 \mathrm{ml}$ of PBS. In the next step, $1 \mathrm{ml}$ of dichlorofluorescein solution was added. The plate was inserted into an aluminum foil and incubated for 30min. After that, the solution in each well was emptied and washed with $1 \mathrm{ml}$ of PBS and read by ELISA at a 450-550nm wavelength.

\section{Annexin V and propidium iodide (PI) assay}

The 10,000 cells were cultured in each well of the 8-well plates (Lab-Tek, Nunc) with three replicates. For control cells, control 1 (without any deprivation and stain), control 2 (annexin V only) and control 3 (PI only) were used and cells were incubated at $37^{\circ} \mathrm{C}$. The cells were then fixed in a methanol-acetone solution $(\mathrm{V} / \mathrm{V})$ for $10 \mathrm{~min}$ at $20^{\circ} \mathrm{C}$. The $400 \mu \mathrm{l}$ of cells $+100 \mu \mathrm{l}$ of incubation buffer with $2 \mu 1$ of annexin V-FITC $(1 \mathrm{mg} / \mathrm{ml})$ and $2 \mu 1$ of PI $(1 \mathrm{mg} / \mathrm{ml})$ was added and placed at $37^{\circ} \mathrm{C}$ for $15 \mathrm{~min}$. In the next step, they were incubated with PI at $20 \mathrm{mg} / \mathrm{ml}$ in the HEPES buffer for $10 \mathrm{~min}$ at room temperature. Then analyze the cells using a flow cytometry without washing the cells (Bio protoc 2013).

\section{Western blotting assay}

The protein was extracted from the $1 \times 10^{6}$ cells and placed on the SDS-PAGE gel. Protein estimation performed using BCA assay, absorbance at $280 \mathrm{~nm}$ for normalizing. The SDS PAGE gel used to purify proteins of the cells. The protein was separated on the gel-protein samples and transferred to the polyvinylidene difluoride (PVDF) membrane and eventually, protein samples that revealed on the PVDF membrane were detected using the ECL kit. After blocking with buffer containing 3\% of ECL advance in PBS/Tween $0.3 \%$ for $1.5 \mathrm{~h}$ at room temperature, the membrane probed with specific polyclonal antibodies (Sigma) diluted in blocking solution (P53 1:7500 and $\beta$-actin) antibodies were added to the membrane $1 \mathrm{~h}$ at room temperature. Then, a secondary antibody added onto the membrane. After the incubation time, the secondary antibodies were removed and washed by tris-buffered saline buffer for 3 to $10 \mathrm{~min}$. Incubate the membrane in the substrate mixture for 10$30 \mathrm{~min}$ until color development. The $\beta$-actin, also as a housekeeping protein, was used as a loading control across the gel. 

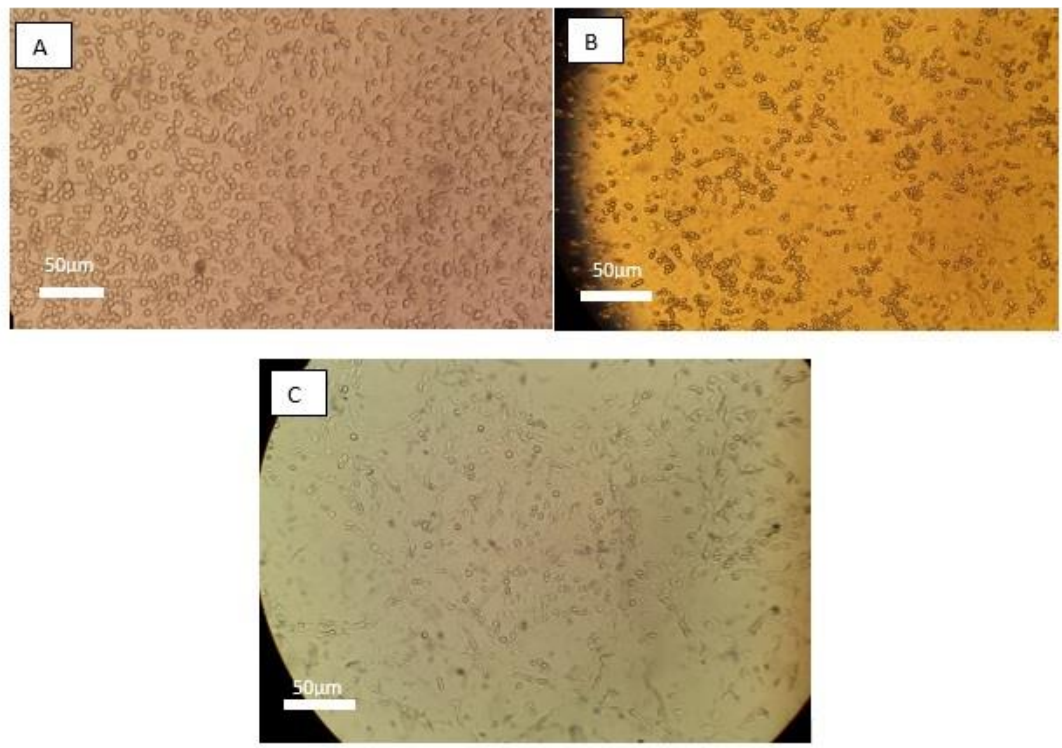

FIGURE 1. Photomicrograph of cells 20X magnification inverted microscope, without oxygen and glucose deprivation (OGD) treatment (A), with OGD treatment (B) and after OGD $+1 \mu \mathrm{M}$ apigenin treatment(C) after $24 \mathrm{~h}$.
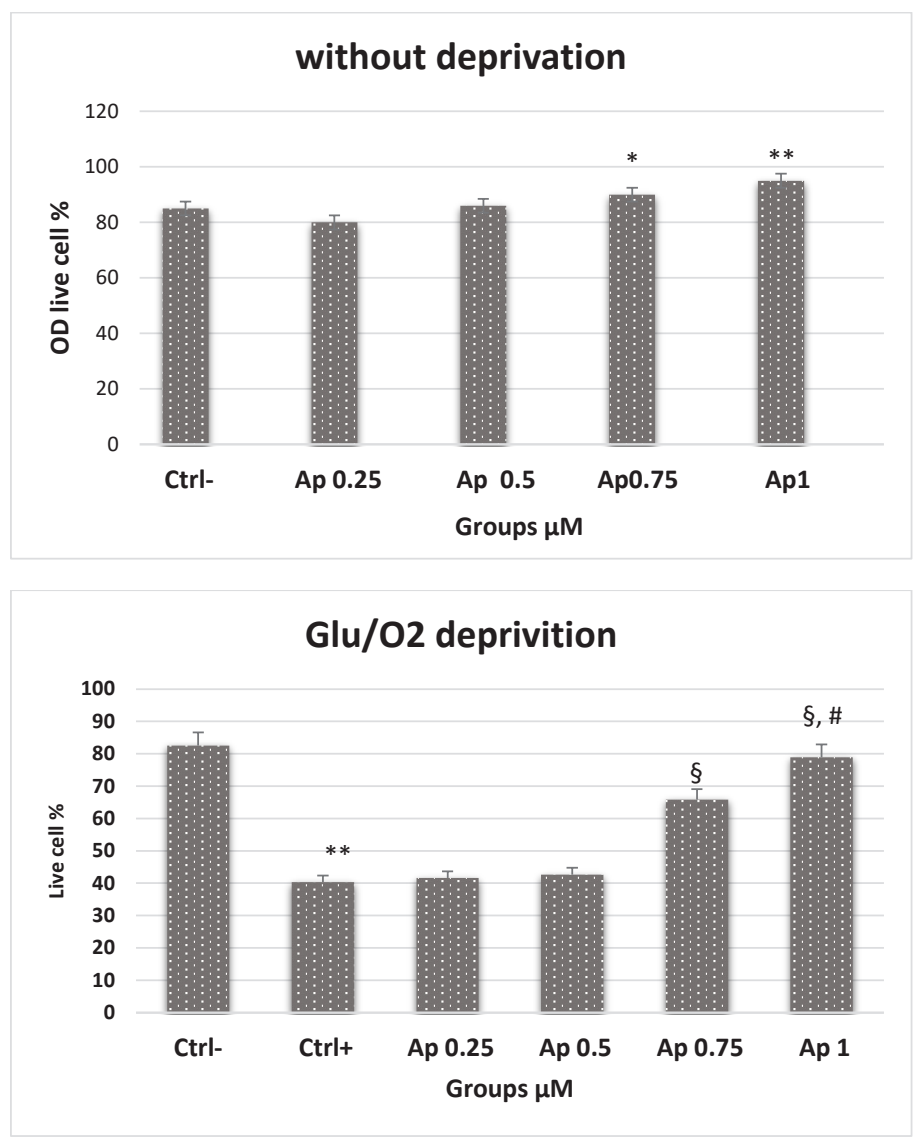

FIGURE 2. The viability OLN 93 cell line results at concentrations of $0.25,0.5,0.75$ and $1 \mu \mathrm{M}$ with and without deprivation conditions. Data are shown based on the mean $\pm \mathrm{SD}$. ${ }^{*} \mathrm{P}<0.01$ significant decrease the positive control compare to experimental groups; §a significant increase with the positive control; \#a significant increase with $0.75 \mu \mathrm{M}$ concentration group.

\section{Statistical analysis}

Data analysis was performed by SPSS version 21, with three replications. The mean \pm SD experimental data evaluated with one-way ANOVA and Duncan test.
The $P$ value $<0.05$ was considered as significant.

\section{Results}

Microscopic results showed the cell morphology 


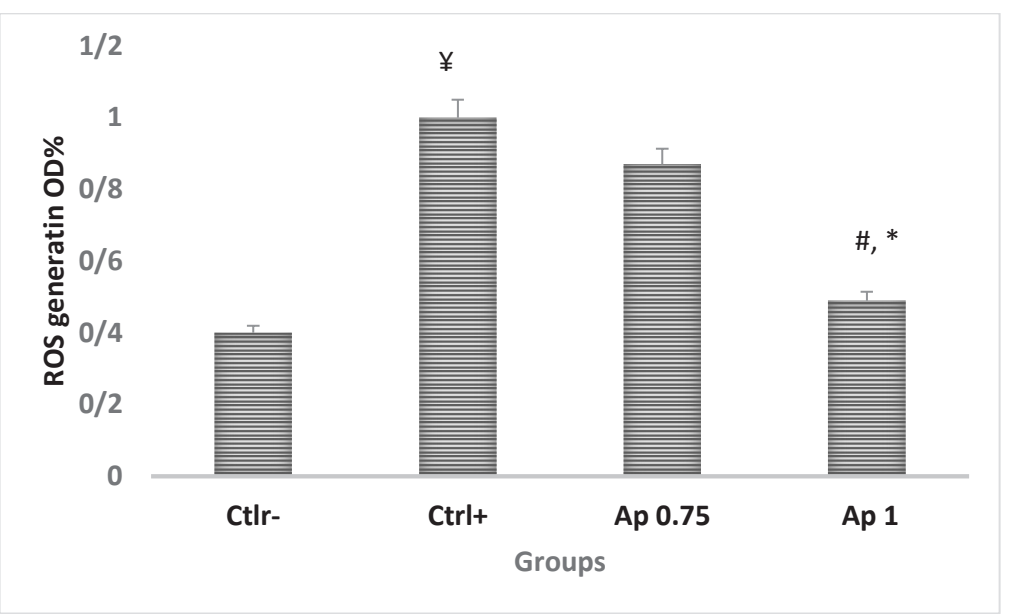

FIGURE 3. Represent the reactive oxygen species (ROS) generation in two concentrations of 0.75 and $1 \mu \mathrm{M}$ with other groups. The data are shown based on mean \pm SD. ¥a significance increased compared to negative control group; \#,*a significant decreased with positive control and $0.75 \mu \mathrm{M}$ concentration, $\mathrm{P}<0.01$
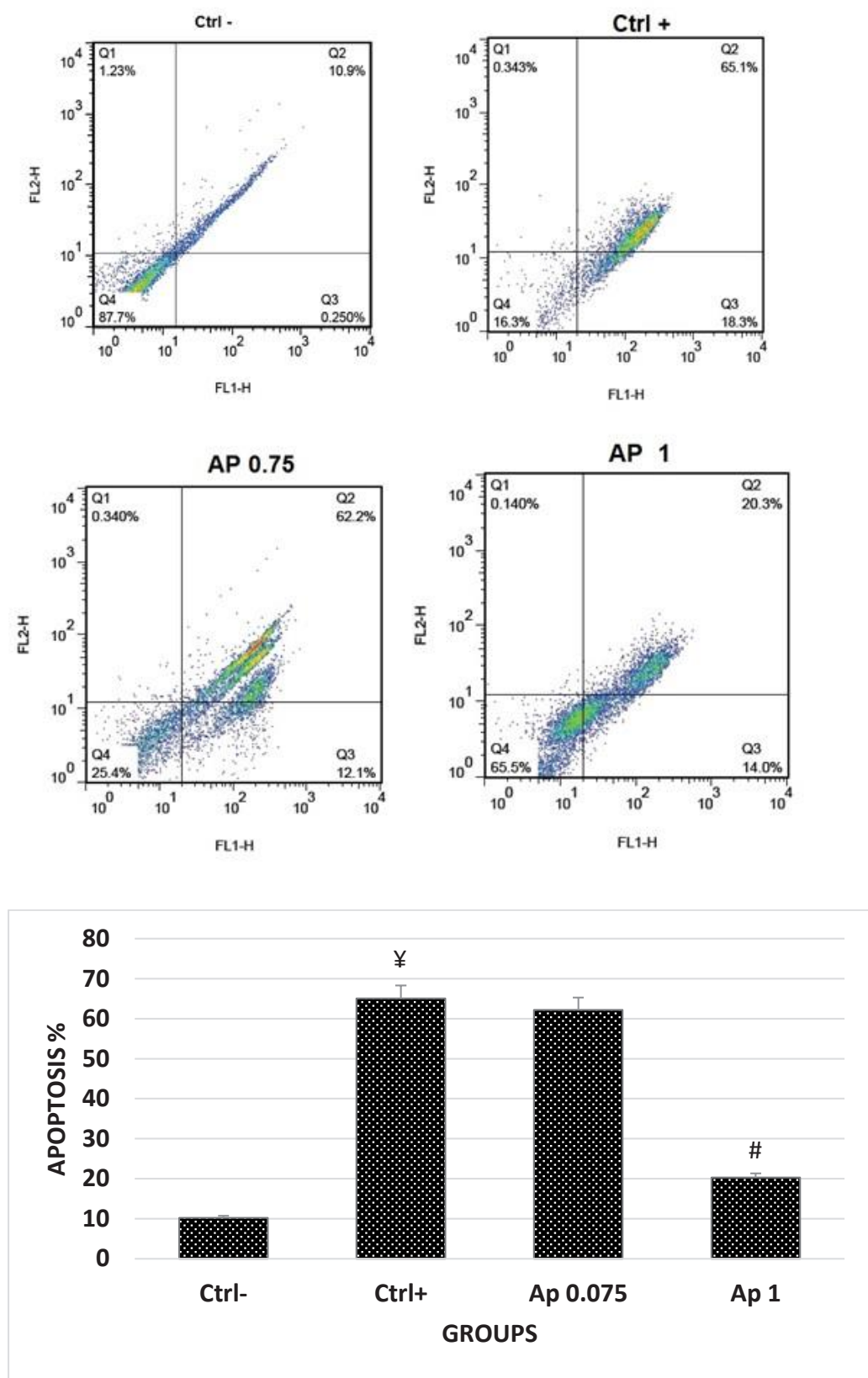

FIGURE 4. The percentage of apoptotic cells by annexin and propidium iodide assay in the groups. ¥a sgnificant increased compared to ctrl-; \#a significant decreased compared to $\mathrm{Ctrl}+$. 


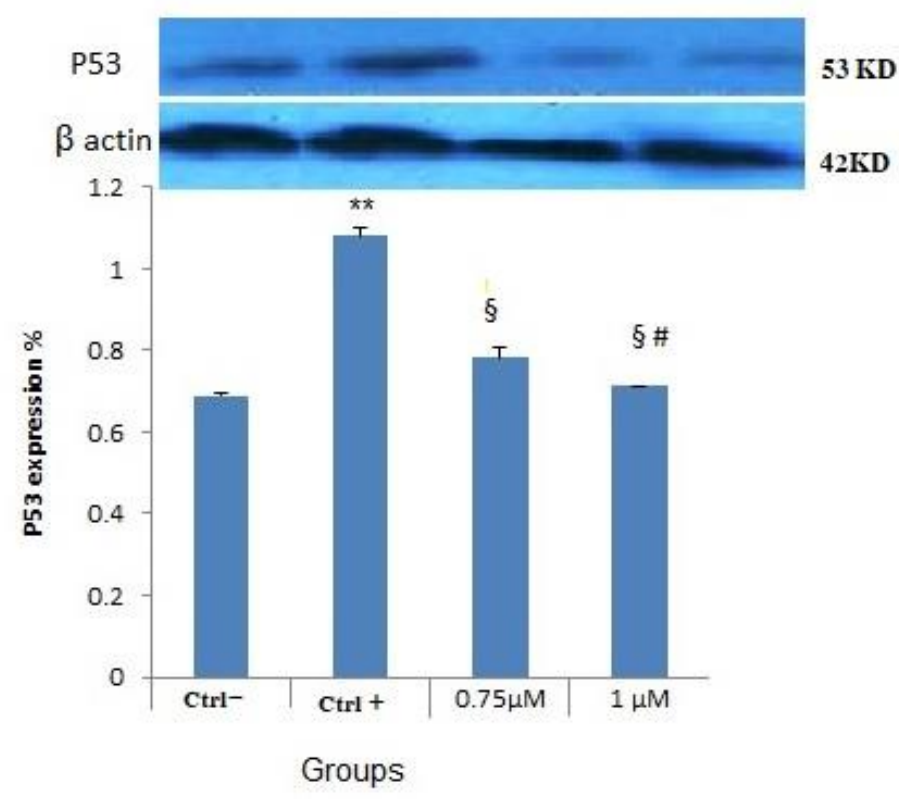

FIGURE 5. Expression of P53 protein in two concentrations of 0.75 and $1 \mu \mathrm{M}$. ${ }^{* *}$ a significant decrease with Ctrl-; ${ }^{\S}$ a significant decrease with $\mathrm{Ctrl}+$; " a significant decrease with $0.75 \mu \mathrm{M}$ concentration.

was changed after OGD treatment. Dead cells were increased, also some cells rounded, granulated and detached of the flask. While after $24 \mathrm{~h}$ apigenin treatment, cells returned to the differential and were attached to the flask (Figure 1).

\section{MTT assay}

OLN-93 cellular viability in oxygen and glucose non-deprivation conditions was studied. The evaluation of viability showed that the cells of the positive control group were degenerated and granulated and were exited from their normal state. The two experimental groups, after the deprivation, were treated with the mentioned concentrations for $24 \mathrm{~h}$. According to the results, the concentrations of $0.75 \mathrm{M}$ and $1 \mu \mathrm{M}$ showed a significant difference compared to the positive control group $(P<0.05)$ and $(P<0.001)$, while the other concentrations did not show a significant increase (Figure 2).

\section{ROS assay}

Generation of ROS under conditions of oxygen and glucose deprivation showed a significant increase compared to the negative control group; while at a concentration of $1 \mu \mathrm{M}$ apigenin treatment showed a significant decrease. This reduction in ROS production between the two concentrations was also significant $(P<0.01$, Figure $3)$.

\section{Annexin assay}

The results of annexin and PI assay showed the apoptotic cell by measurements of phosphatidyl serein that is transmitted to the membrane surface during apoptosis. Data showed a significant reduction in the percentage of apoptotic cells from $65.1 \%$ to $20.3 \%$ in the $1 \mu \mathrm{M}$ apigenin treatment group. The percentage of live cells in the positive control group was $16.3 \%$, which showed a significant increase to $65.5 \%$ in the $1 \mu \mathrm{M}$ apigenin treatment group. The reduction of apoptosis also had a significant difference between the two apigenin treatment groups (Figure 4).

\section{Western blotting}

According to Figure 5, the expression of P53 protein in oligodendrocyte OLN93 cells in the negative control group was significantly lower than to positive control group. The amount of this protein decreased significantly after treatment with $1 \mu \mathrm{M}$ and $0.75 \mu \mathrm{M}$ of the apigenin compared to the positive control group. Also, there was a significant difference in the reduction of P53 level in comparison with two concentrations of apigenin treatment.

\section{Discussion}

Stroke is one of the most common diseases in many societies that leads to certain disabilities. Many efforts have been made to reduce the sequelae and side effects 
of stroke. Many researchers consider the use of plant substances such as flavonoids. Apigenin is a flavonoid with antioxidant effects known for its protective effects on cardiovascular disease, cancer and nerve damage (Balez et al., 2016; Duarte et al., 2013; Solanki et al., 2016). Since oligodendrocyte damage plays a role in the progression of neurological diseases, the aim of this study was to investigate the protective effect of apigenin on oligodendrocyte cell line. According to the study conducted by Souza et al. in 2015, apigenin in multipotent and pluripotent stem cells increases the expression of neuronal markers such as $\beta$-tubulin-III, microtubule-associated protein 2 , polysialylated-neural cell adhesion molecule, synapsin 1 and neurofilament that leads to neuronal differentiation. Our results showed that the cells were exposed to OGD, a significant reduction in viability occurred and treatment with different concentrations of apigenin prevented the death of these cells and increased the number of oligodendrocytes. This increase in concentration of $1 \mu \mathrm{M}$ apigenin was more significant than $0.75 \mu \mathrm{M}$ apigenin. Also, microscopic observations showed differentiation of oligodendrocyte cells. According to Souza et al. study, differentiation factors appear to inhibit apoptosis under the influence of apigenin in addition to the possible promotion of neuronal cell growth and proliferation. Duarte et al. (2013) showed that apigenin could reduce lipopolysaccharide toxicity in endothelial cells. They reported that $1 \mu \mathrm{M}$ apigenin decreases cell death by reducing the expression of caspase 3 protein. Regarding their results and also ours in the present study, we think the same mechanisms might be effective for oligodendrocyte. Oxidative stress was reported for the pathophysiology of certain neurological disorders. During the oxidative stress, free radicals release more than the capacity of the cells to suppress them. As a polyphenol, apigenin has the ability to inhibit and suppresses the action of free radicals and ROS production. Our results showed that $1 \mu \mathrm{M}$ of apigenin reduced ROS production. This finding confirmed the antioxidant effects of apigenin in certain types of cells. Annexin assay in the present study showed that following a decrease in the production of ROS, the number of apoptotic cells decrease in the treated cell line that decrease in apoptosis was due to a decrease of P53 protein expression. This results revealed that apigenin can affect mitochondria and nuclei by penetrating into the cell. Also according to suzoa report, this mechanism regulate by caspase 3 .

The P53 known as the pathogenic factors with a pivotal role in neurodegenerative disease and neuronal loss. Szybińska and Leśniak (2017) reported that p53 level and activity in neurons could increase not only as a result of oxidative stress and DNA damage but also due to aberrant regulation of its expression by mutated or erroneously cleaved proteins involved in neurodegeneration. Increased expression and activation of p53 entails the enhanced expression of genes responsible for apoptosis or/and cell cycle arrest and in consequence, may trigger neuronal death.

In 2016, the neuroprotective effect of apigenin against inflammation, neuronal excitability and apoptosis in an induced pluripotent stem cell model of Alzheimer's disease was studied. Balez et al. comprehensively studied the different mechanisms of apigenin neuroprotection functions. They showed the anti-inflammatory, anti-oxidant and anti-apoptotic properties of apigenin. For anti-inflammatory effect of apigenin, they claimed that apigenin suppresses inflammation via inhibiting the activation of cytokines and the production of nitric oxide. According to them, apigenin is able to protect neurons by reducing nitric oxide levels of activity in neuroglia cells. They reported the possible mechanism of the anti-apoptotic effect via decrease of caspase 3/7 activity. In addition, to the mechanisms reported by Balez et al., the anti-oxidant and anti-apoptotic properties of the apigenin can be created by influencing the expression of Nrt2, P53 and the transcription of the down-stream target genes (Zhang et al., 2014). Reducing neural hyper-excitability and $\mathrm{Ca}^{2+}$ dysfunction also supposed for the protective effect of apigenin. According to our results and other reports, we think that the same mechanisms or pathways might be responsible for the protective effects of apigenin on oligodendrocyte cells. It has also been shown that apigenin flavonoid reduces the inflammatory response induced by Lipopolysaccharides in macrophages, by inhibiting the release of inflammatory mediators via blocking the NF-Kb activity pathways. Pang et al. (2018) in their in vivo and in vitro studies claimed for another property for apigenin in cerebral ischemic injury via the caveolin-1 signaling pathway that leads to angiogenesis, cell proliferation and vascular endothelial growth and transcription factor activation. Despite that all these findings, confirm the protective effects of apigenin via different mechanisms and pathways, it seems 
that there is a dose-dependent manner in the efficacy of apigenin that showed in our results too.

\section{Conclusion}

Collectively, we used oligodendrocyte cell line OLN93 because it plays an important role in protecting neurons and these cells can improve the adverse effects of stroke. Based on our result the protective property of apigenin depending on certain does. The reduction of P53 and ROS production considered a possible mechanism of apigenin activity. Although certain mechanisms reported by other researchers, further study needs for explaining precise mechanisms.

\section{Acknowledgments}

The authors are deeply grateful to colleagues and laboratory staff of NRC/IUMS for their sincere collaboration and also Vice Chancellor of Research and Technology. The present research supported by the Neuroscience Research Center of Iran University of Medical Science and Islamic Azad University Karaj Branch.

\section{Conflict of interest}

The authors declare no conflict of interest.

\section{Reference}

Balez R, Steiner N, Engel M, Munoz S, Lum J, Wu Y, et al. Neuroprotective effects of apigenin against inflammation, neuronal excitability and apoptosis in an induced pluripotent stem cell model of Alzheimer's disease. Sci Rep 2016; 6: 1-6. https://doi.org/10.1038/srep31450

Caltagirone S, Rossi C, Poggi A, Ranelletti FO, Natali PG, Brunetti $\mathrm{M}$, et al. Flavonoids apigenin and quercetin inhibit melanoma growth and metastatic potential. Int $\mathrm{J}$ Cancer 2000; 87: 595-600. https://doi.org/10.1002/10970215(20000815)87:4<595::AID-IJC21>3.0.CO;2-5

Duarte S, Arango D, Parihar A, Hamel P, Yasmeen R, Doseff A. Apigenin protects endothelial cells from lipopolysaccharide (LPS)-induced inflammation by decreasing caspase-3 activation and modulating mitochondrial function. Int J Mol Sci 2013; 14: 17664-79. https://doi.org/10.3390/ ijms140917664

Haghiroalsadat BF, Vahidi AR, Azimzadeh M, Kalantar SM, Bernard F, Hokm EF. Chemical assessment of active ingredients and anti-oxidant effects of trachyspermum copticum'sseeds harvested in yazd province. J Rafsanjan Univ Med Sci Health Serv 2012; 196-206.
Kim SJ, Jin YH, Kim BS. Prostaglandin E2 produced following infection with Theiler's virus promotes the pathogenesis of demyelinating disease. PloS One 2017; 12: e0176406 https://doi.org/10.1371/journal.pone.0176406

Li ZD, Hu XW, Wang YT, Fang J. Apigenin inhibits proliferation of ovarian cancer A2780 cells through Id1. FEBS letters 2009; 583: 1999-2003. https://doi.org/10.1016/j.febslet.2009.05.013

Logan A, Freeman J, Kent B, Pooler J, Creanor S, Vickery J, et al. Standing Practice In Rehabilitation Early after Stroke (SPIRES): a functional standing frame programme (prolonged standing and repeated sit to stand) to improve function and quality of life and reduce neuromuscular impairment in people with severe sub-acute stroke-a protocol for a feasibility randomised controlled trial. Pilot Feasibility Stud 2018; 4: 1-8. https://doi.org/10.1186/s40814-0180254-Z

Miean KH, Mohamed S. Flavonoid (myricetin, quercetin, kaempferol, luteolin, and apigenin) content of edible tropical plants. J Agric Food Chem 2001; 49: 3106-12. https:// doi.org/10.1021/jf000892m

Nabavi SF, Khan H, D’onofrio G, Šamec D, Shirooie S, Dehpour AR, et al. Apigenin as neuroprotective agent: Of mice and men. Pharmacol Res 2018; 128: 359-65. https://doi. org/10.1016/j.phrs.2017.10.008

Pang Q, Zhao Y, Chen X, Zhao K, Zhai Q, Tu F. Apigenin protects the brain against ischemia/reperfusion injury via caveolin-1/VEGF in vitro and in vivo. Oxid Med Cell Longev 2018; 2018. https://doi.org/10.1155/2018/7017204

Solanki I, Parihar P, Mansuri ML, Parihar MS. Flavonoid-based therapies in the early management of neurodegenerative diseases. Adv Nutr 2015; 6: 64-72. https://doi. org/10.3945/an.114.007500

Solanki I, Parihar P, Parihar MS. Neurodegenerative diseases: from available treatments to prospective herbal therapy. Neurochem Int 2016; 95: 100-8. https://doi.org/10.1016/j. neuint.2015.11.001

Souza CS, Paulsen BS, Devalle S, Lima Costa S, Borges HL, Rehen SK. Commitment of human pluripotent stem cells to a neural lineage is induced by the pro-estrogenic flavonoid apigenin. Advance Reg Biol 2015; 2: 29244. https://doi. org/10.3402/arb.v2.29244

Su W, Matsumoto S, Banine F, Srivastava T, Dean J, Foster $\mathrm{S}$, et al. A modified flavonoid accelerates oligodendrocyte maturation and functional remyelination. Glia 2020; 68: 263-79. https://doi.org/10.1002/glia.23715

Szybińska A, Leśniak W. P53 dysfunction in neurodegener- 
ative diseases-the cause or effect of pathological changes? Aging Dis 2017; 8: 506. https://doi.org/10.14336/ AD.2016.1120

Taupin P. Apigenin and related compounds stimulate adult neurogenesis: Mars, Inc., the Salk Institute for Biological Studies: WO2008147483. Expert Opin Ther Pat 2009; 19: 523-7. https://doi.org/10.1517/13543770902721279

Tornabene E, Helms HC, Pedersen SF, Brodin B. Effects of oxygen-glucose deprivation (OGD) on barrier properties and mRNA transcript levels of selected marker proteins in brain endothelial cells/astrocyte co-cultures. PloS
One 2019; 14: e0221103. https://doi.org/10.1371/journal. pone.0221103

You Y, Joseph C, Wang C, Gupta V, Liu S, Yiannikas C, et al. Demyelination precedes axonal loss in the transneuronal spread of human neurodegenerative disease. Brain 2019; 142: 426-42. https://doi.org/10.1093/brain/awy338

Zhang X, Wang G, Gurley EC, Zhou H. Flavonoid apigenin inhibits lipopolysaccharide-induced inflammatory response through multiple mechanisms in macrophages. PLoS One 2014; 9: e107072. https://doi.org/10.1371/journal. pone. 0107072 